\title{
210 Mw Turbo Generator's Hydrogen Gas Cooling System Online Monitoring and Controlling using Node Red Flow Based IoT
}

\author{
K. Dwarakesh, Rathika R, Aarthi Suriya S
}

\begin{abstract}
This undertaking is about plan and execution of remote observing and controlling of 210 MW TURBO GENERATOR'S HYDROGEN COOLING SYSTEM utilizing NODE RED BASED IOT PROGRAM. The quicker heat scattering of generators in power plants calls for hydrogen cooling, and water is utilized as coolant to chill off the hot hydrogen which turns out from the hydrogen cooling framework (HCS) at the producing end. Along these lines, in enormous creating plants, the way toward cooling and the coolant become basic pieces of the warmth exchangers. Subsequently, necessity of a dependable HCS is an unquestionable requirement. The primary point of this task is to naturally refill the hydrogen gas in the hydrogen cooling arrangement of turbo generators at whatever point the hydrogen level gets diminished than the ideal hydrogen level. This framework functions admirably in both ordinary necessity conditions and furthermore during basic prerequisite conditions, when there is a surprising spillage in the framework. The whole procedure control and observing, famously known as human-machine interface of HCS, has been created and reproduced on NODE RED BASED IOT PROGRAM. [1],[ $3],[5]$
\end{abstract}

Keywords : nline Generator HCS Monitor, Auto and Remote HCS Monitor, Generator's Hydrogen Pressure Level, Auto Refill of Hydrogen, Hydrogen Cylinder's Pressure Level,ADS1115 ADC, Node-RED, Raspberry pi3B+, Blynk.

\section{INTRODUCTION}

A warm power station is a power plant in which the fundamental power is steam driven. Water is warmed, transforms into steam and twists a turbine which drives an electrical generator. [2 ],[ 4],[6]

\section{A.210MW TURBO GENERATOR:}

The stator body is completely encased gas tight manufactured structure, reasonably ribbed inside to guarantee high unbending nature. It is structured precisely to withstand inward weight and powers because of [8],[10],[12]

far-fetched occasion of blast of hydrogen and air blend with no remaining disfigurement. The Hydrogen gas coolers are housed longitudinally inside the stator body. The stator center is comprised of segmental varnished punching of Electro specialized sheet steel with low misfortune factor. The stator has a three stage, twofold layer, short pitched and bar sort of windings having two parallel ways. Each opening suits two bars. Each bar comprises of strong just as empty conductors with cooling water going through. The stator bar protection is finished with epoxy mica thermosetting protection. The stator bar top and base are associated by methods for copper channels at exciter end. The PTFE hoses are associated between areola on the stator bar and areola on the gulf and outlet water headers at turbine end. The stator winding temperature is estimated by 60 nos. RTDS and 12 nos. of backup RTDS. The rotor shaft is comprised of chromium nickel molybdenum and vanadium steel, the rotor winding is comprised of silver bearing copper and rotor opening wedges are comprised of Duraluminium. The rotor windings are cooled by methods for direct cooling strategy .of hole get technique. In this kind of cooling the hydrogen in the hole is sucked through the circular openings filling in as scoop on the rotor wedges and it is coordinated to stream along horizontal vent pipes on rotor copper curl to base of the loop. The rotor cooling gas is coursed by two single stage hub stream propeller type fans. The slip rings are associated with the field twisting through semi adaptable copper leads and current conveying jolt set radially in the pole. [7],[ 9], [11]

So as to keep the getaway of hydrogen from generator packaging along the rotor shaft, shaft seals gave oil under strain are utilized. The pole seal is furnished with seal oil by a different shut circuit framework. To guarantee free development of the fixing, the pole seals are furnished with weight oil for ring help from overseeing oil framework. The seal oil provided to the pole seals, are depleted from both air and hydrogen sides. The air side seal is legitimately depleted to the seal oil tank. The oil depleted towards hydrogen side is gone through prechambers and transitional oil tank before depleting to the seal oil tank. Temperature is regulated constantly by checking seal oil stream and seal oil temperature. For visual keep an eye on the progression of the oil towards hydrogen side, oil check funnels are given at either part of the bargain. 


\section{TECHNICAL DATA:}

Max.ContinuousKVA Rating:247000KVA

Max. Continuous KW Rating: 210000KW

Rated Terminal Voltage: $15750 \mathrm{~V}$

Rated Stator Current: 9050A

Rated Power Factor: 0.85 lag

Excitation Current at MCR condition: 2600A

Excitation Voltage at MCR condition : 310V

Rated Speed : 3000RPM

Rated frequency: $50 \mathrm{~Hz}$

Efficiency at MCR condition : $98.55 \%$

Negative sequence : $122 \mathrm{t}=8$

Direction of rotation when viewed from slip ring: clockwise Phase connection: Double star

No.of. Terminals brought out: 9 (6 neutral and 3 Phase)

Total gas volume of generator: 56 cum.

Nominal Pressure of Hydrogen:3.5KG/Sq.cm

Permissible variations: $+0.2 \mathrm{Kg} / \mathrm{Sq} . \mathrm{cm}$

Maximum temperature of cold gas: $44 \mathrm{deg} \mathrm{C}$.

Purity of Hydrogen (min): 97\%

\section{B.HYDROGEN GAS SYSTEM:}

The Hydrogen gas is used as cooling medium in generator because of its higher heat transfer capacity and light weight. However it is having the property of formin and explosive mixture when mixes with air. But the risk of explosion is almost eliminated, when the Hydrogen gas quantity is less than $4 \%$ or more than $74 \%$. So, in generator wherein hydrogen gas is employed in closed circuit, the purity has to be always maintained beyond $90 \%$, a hydrogen gas purity of about $99 \%$ is maintained inside the generator casing.

The Hydrogen gas system performs the following functions:Provides means for safety filling of hydrogen gas into or purging out of, the machine.Maintains gas pressure inside the machine at the desired value.Indicates the operator, at all times the condition of the gas in the machine, its pressure and purity.Removes moisture from the gas in the machine which may get into it from seal oil. [13], [15] , [17]

\section{C.TECHNICAL DATA:}

Rated hydrogen pressure inside generator casing: $3.5 \mathrm{Kg} / \mathrm{cm}^{2}$ Maximum hydrogen pressure at which signal is initiated: $3.7 \mathrm{Kg} / \mathrm{cm}^{2}$

Minimum hydrogen pressure at which signal is initiated: $3.3 \mathrm{Kg} / \mathrm{cm}^{2}$

Rated cold gas temperature: $44^{\circ} \mathrm{C}$

Max. Permissible hot gas temperature: $75^{\circ} \mathrm{C}$

Min. Purity of hydrogen permissible: $97 \%$

Max. Permissible moisture content in hydrogen: $4500 \mathrm{ppm}$

Generator gas volume: 56 cu.m

\section{DESIGN AND IMPLEMENTATION OF PROPOSED SYSTEM:}

The prototype model of the proposed system is represented in simple in the block diagram representation as shown in the figure

\section{Block Diagram}

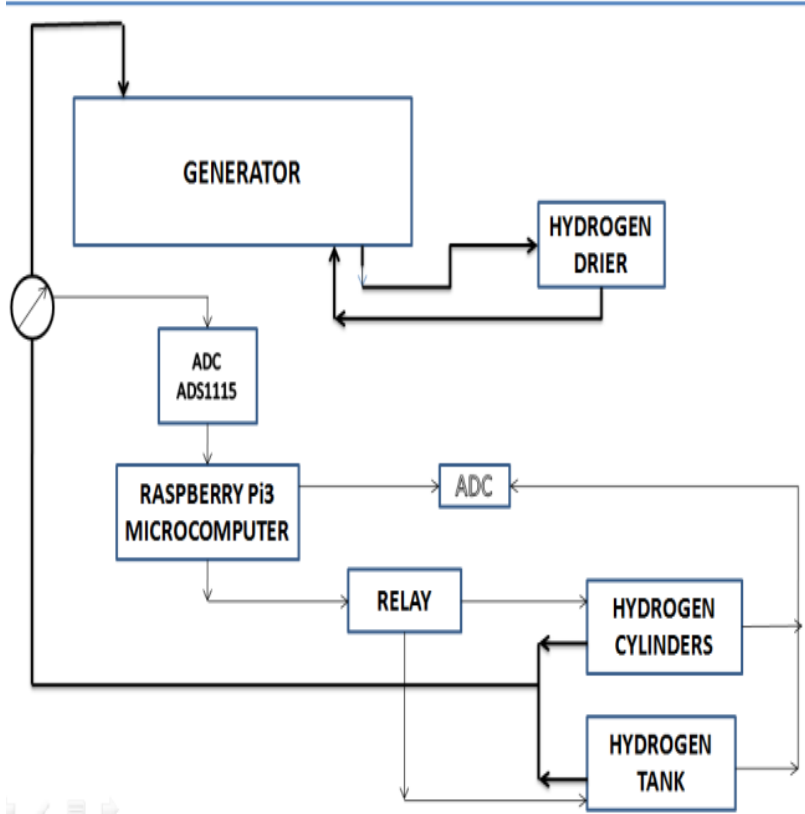

Fig.1. Block diagram representation of proposed 210MW Turbo Generator Online Monitoring and Controlling

In the proposed system, the hydrogen gas level is automatically monitored and controlled using smart monitoring and controlling system. The hydrogen gas is automatically refilled during normal requirement conditions.During critical requirement conditions, the hydrogen level is still maintained,even when there is a leakage in the system. The leakage can be traced and fixed without tripping off the entire unit. This ensures continuous and reliable functioning of the unit. [14], [ 16], [18]

\section{A. Microcomputer}

A movement of minimal single board PCs is used to create Raspberry Pi. It was made in the United Kingdom by the Raspberry Pi Foundation to propel the educating of major programming designing in schools and in making countries. The Raspberry Pi gear has created through various variations that has assortments in memory point of confinement and periphery device support. The proposed procedure is completed using RASPBERRY PI 3 MODEL B. The Raspberry PI 3 Model B is the latest variation of the Raspberry PI. They are charge card sizecomputer. Incorporate a comfort, mouse, appear, control supply, little scale SD card with Linux apportionment and NODE RED. You will have a verifiable PC that can run application from word processor and spreadsheet.It has a Dual-Band wi-fi incorporate. This Wi-Fi engaged microcomputer can be related with PCs by using web HMI to screen the parameters remotely. [19],[20],[21]

\section{B. ADS1115ADC Convertor}

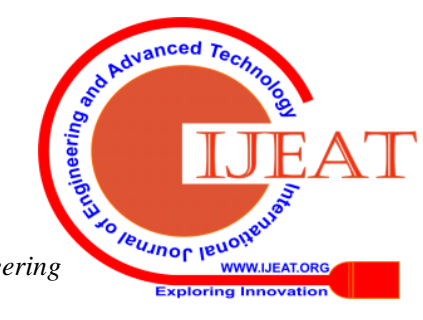


The ADS1115 4-channel breakout sheets are ideal for adding simple to computerized signal transformation to any microchip based undertaking. These sheets keeps running with power and rationale flag between $2 \mathrm{v}$ to $5 \mathrm{v}$, so they work with all basic $3.3 \mathrm{v}$ and $5 \mathrm{v}$ processors. The same number of 4 of these sheets can be controlled from a similar 2-wire I2C transport, offering up to 16 single-finished or 8 differential channels. A programmable increase speaker offers up to x16gain for little signals.The ADS1115 has higher resolution.ThisADS1115 ADC convertor gets the simple temperature signal from RTD and sends the computerized information sign to microcomputer.

\section{SOFTWARE}

\section{A.Node-RED}

Hub RED is a stream based advancement apparatus created by IBM for wiring equipment gadgets together, APIs and online administrations as a feature of the Internet of Things. The browser UI is a graphical representation of flow where drag and drop node templates are connected together. Each node template is a pre-defined set of java script code. This is designed to carry out particular functions as per the user defined values or device functionality. The node templates gets stored in the node palette and it is divided into predefined groups like input, output or functions. Input and output nodes varies from injections to connection types such as TCP, Web Sockets or MQTT. Function nodes permits the user defined functions, switches, delays and triggers to interact between output and input nodes. The browser UI provides execution and committing point for flows to the run time.

\section{B. Blynk}

Blynk Server is an Open-Source Nett based Java Server. It is responsible for sending messages from Blynk convenient application to various little scale controller sheets and SBCs.Blynk is an Internet of Things arrange. It hopes to improve building adaptable and web applications for the Internet of Things.

\section{IV.SIMULATION DESIGN AND IMPLEMENTATION}

Hub RED is a stream based advancement device created by IBM for wiring equipment gadgets together, APIs and online administrations as a component of the Internet of Things. The browser UI is a graphical representation of flow where drag and drop node templates can be connected together. Here we use Simulink tools for developing this project with good efficiency in developing. This paper consists of two sections software and hardware. In software section all tests are done in Node-RED software and the simulation was done in Node-RED and the simulation result is as follows.

Hydrogen level alert message if hydrogen level decreases below the set point range.

1. Automatic opening of non return solenoid valve of the Hydrogen Cylinder 1 when the hydrogen pressure level in the generator decreases below the desired level.

2. Automatic closing of non return solenoid valve of the Hydrogen Cylinder 1 when the hydrogen pressure level in the generator reaches the desired level.

3. Alert message when the hydrogen cylinder becomes empty.
4. When the hydrogen pressure level in the generator decreases again, the same procedure is followed with hydrogen cylinders 2, 3 and 4 respectively.

5. Alert messages will be sent to the reporting engineers when each hydrogen cylinder gets empty.

The Node-RED dashboard for this project is as follows.

\section{A.TURBO GENERATOR ONLINE HYDROGEN PRESSURE MONITORING \& CONTROL SYSTEM USING IOT.}

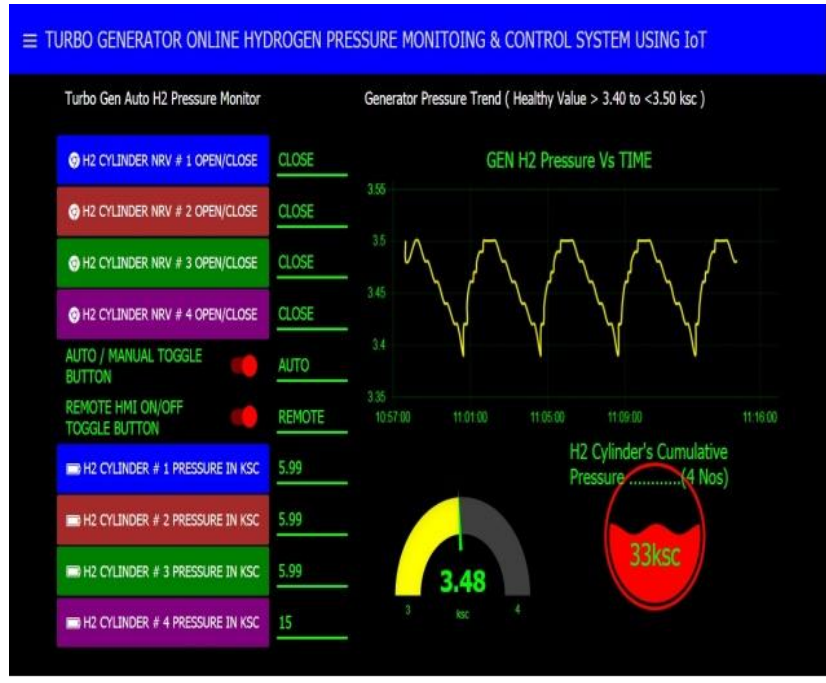

\section{B. SPARE CYLINDER HYDROGEN PRESSURE GAUGE}

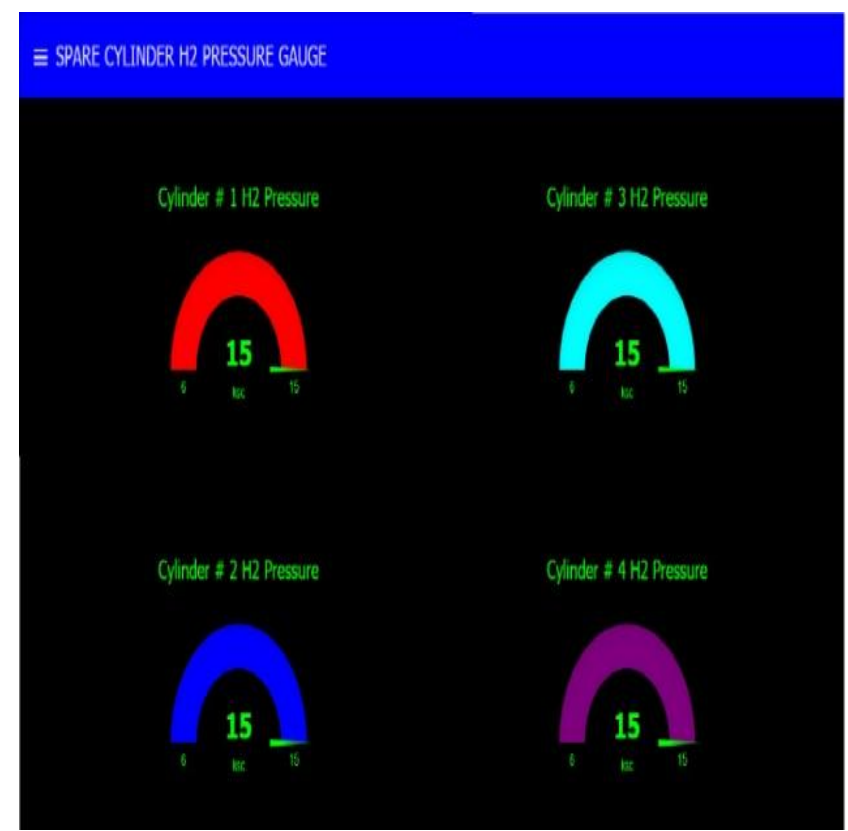


210 Mw Turbo Generator's Hydrogen Gas Cooling System Online Monitoring And Controlling Using Node Red Flow Based IoT

\section{C.210 MW TURBO GENERATOR ELECTRICAL} PARAMETERS

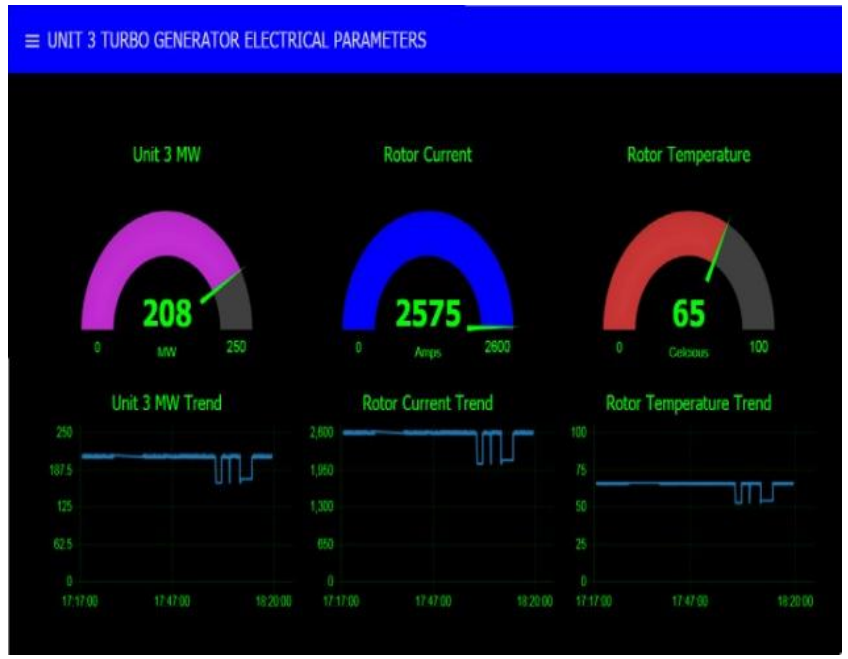

\section{D.SPARE CYLINDER PRESSURE TREND}

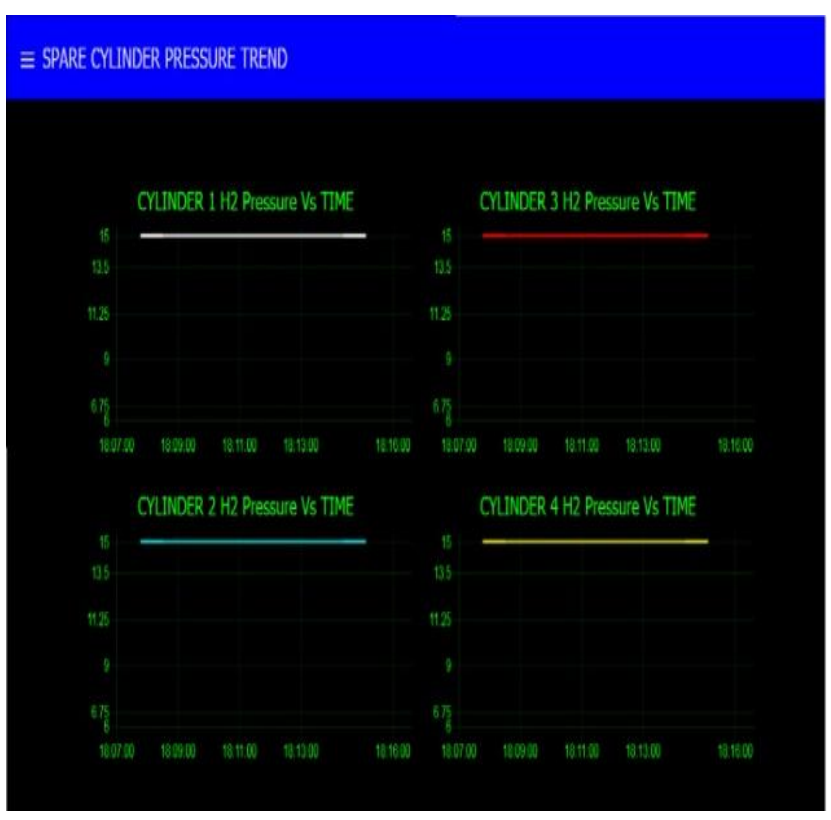

\section{E. MOBILE MONITORING AND CONTROL}

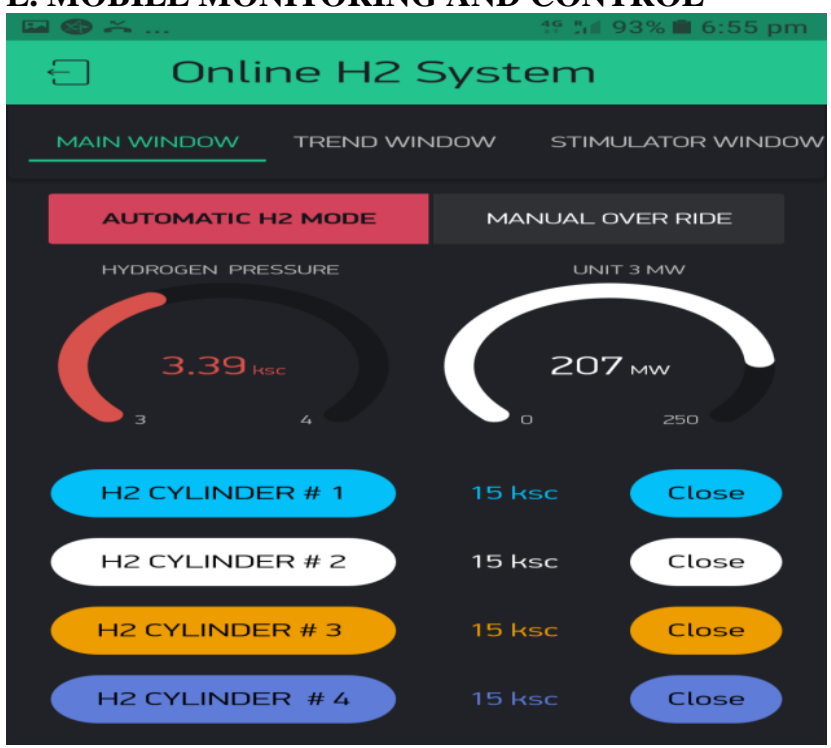

Retrieval Number: F10180886S219/2019@BEIESP

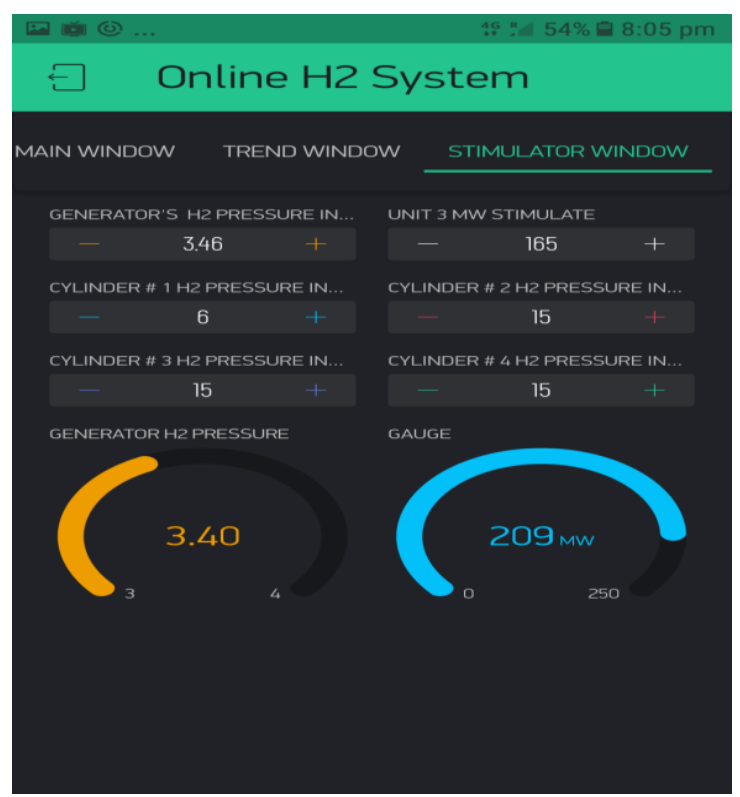

\section{V.SIMULATION RESULTS}

A.OUTPUT WAVE FORM OF TURBO GENERATOR HYDROGEN PRESSURE

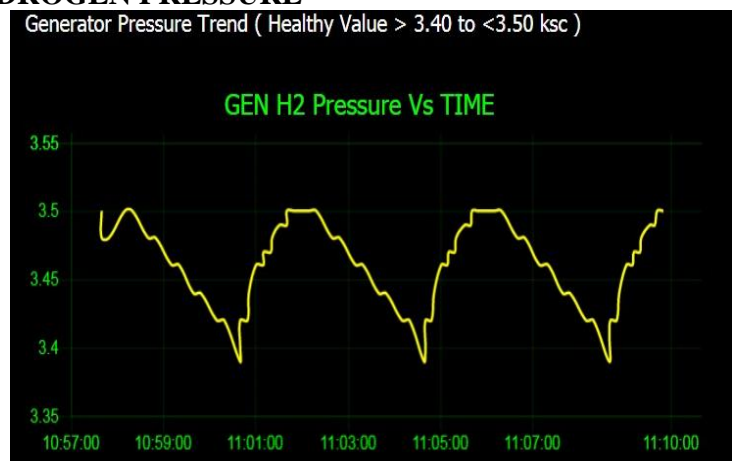

\section{B. OUTPUT OF HYDROGEN CYLINDER 1}

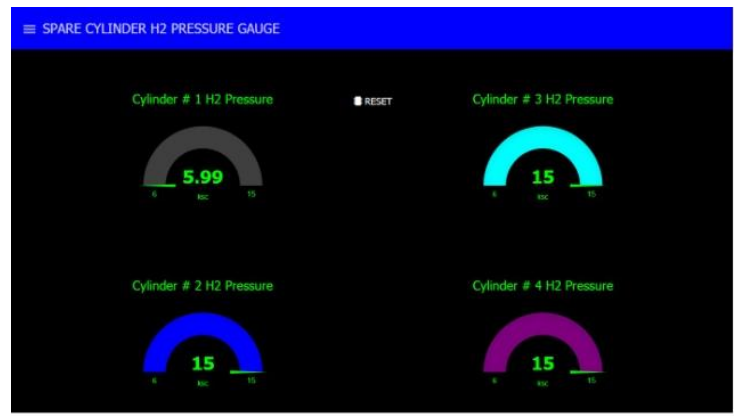

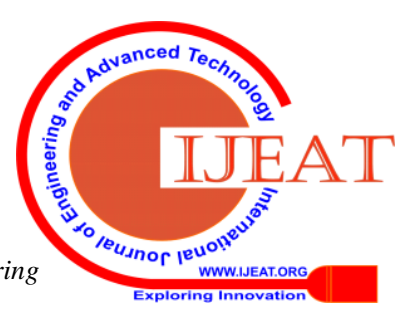


International Journal of Engineering and Advanced Technology (IJEAT) ISSN: 2249 - 8958, Volume-8 Issue-6S2, August 2019
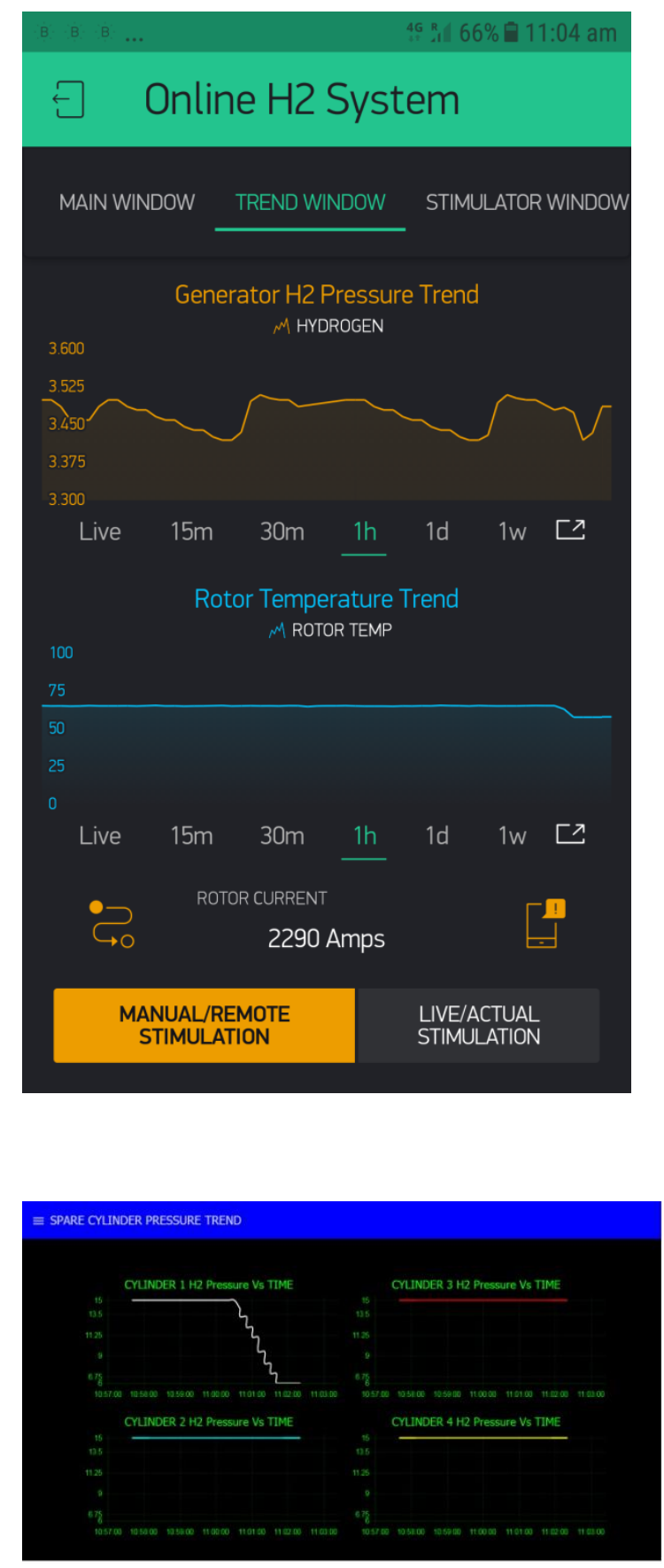

\section{OUTPUT OF HYDROGEN CYLINDER 2}

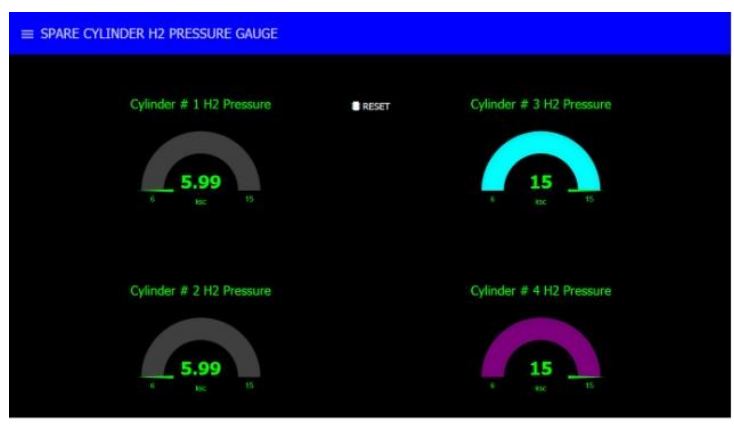

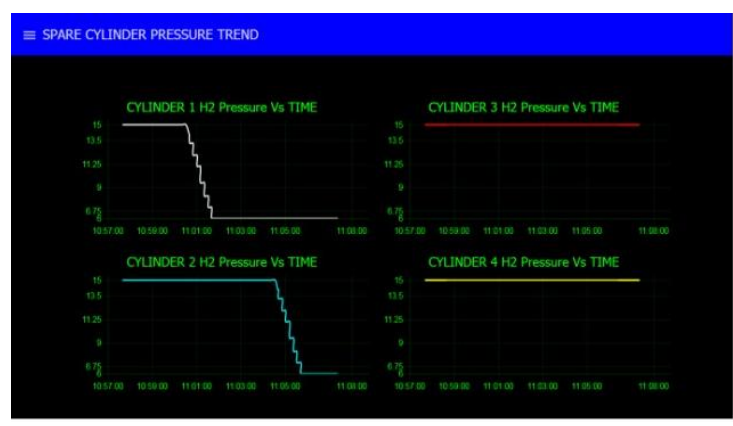
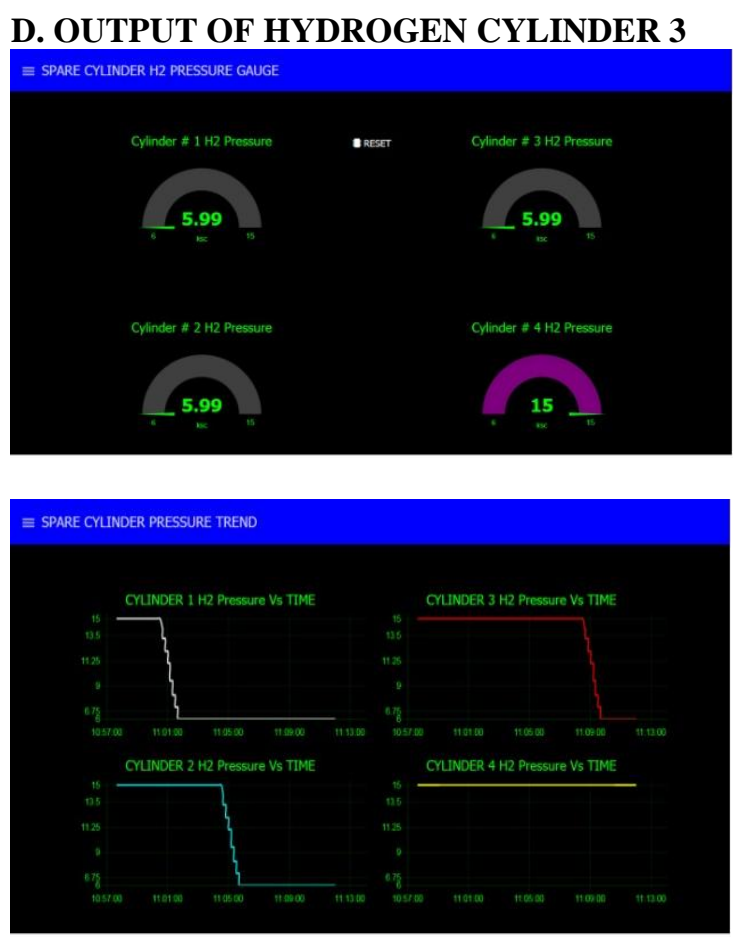

\section{E. OUTPUT OF HYDROGEN CYLINDER 4}
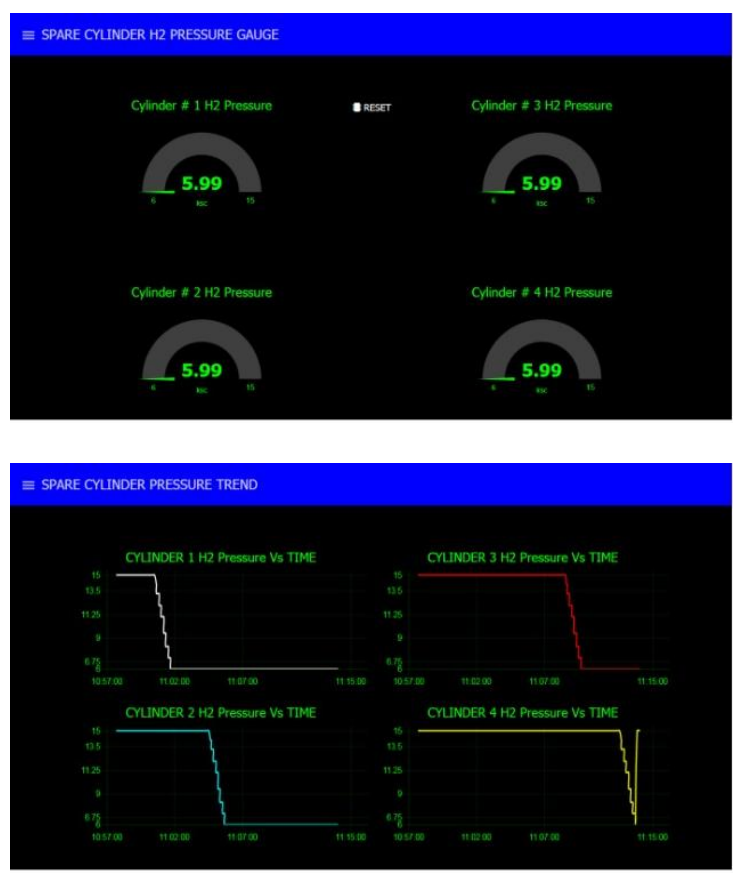


\section{Conclusion}

I designed an automatic system to view, monitor and fill the Hydrogen gas cooling system in a more efficient and reliable method. In the existing system, manpower is required to fill the Hydrogen gas cooling system . This system is purely a manual process and consumes more time and less reliable. The proposed system allows us to automatically view, monitor and refill the Hydrogen gas cooling system using Raspberry Pi 3 model. I also incorporate Node Red method in Raspberry Pi3 model to provide a complete automated system. Thus this project provides a solution for all the drawbacks in the existing system.

\section{REFERENCES}

[1] Sharma, R.K., Irusapparajan, G. \& Periyaazhagar, D. 2019 "Three-phase symmetric cascading Z-source seven levels multilevel inverter excited by multi carrier sinusoidal pulse width modulation scheme", International Journal of Innovative Technology and Exploring Engineering, vol. 8, no. 10, pp. 4269-4274.

[2] Velavan, R., Bharanidharan, S. \& Sheeba, B. 2019, "EMF pollution Causes, effects and protection", International Journal of Innovative Technology and Exploring Engineering, vol. 8, no. 9 Special Issue 3, pp. 1166-1168.

[3] Saravana, S., Balaji, S., Arulselvi, S. \& John Paul Praveen, A. 2019 "Reliable power quality monitoring and protection system", International Journal of Innovative Technology and Exploring Engineering, vol. 8, no. 9 Special Issue 3, pp. 644-645.

[4] Tamil Selvan, S. \& Sundararajan, M. 2019, "Performance Parameters of 3 Value $8 \mathrm{t}$ Cntfet Based Sram Cell Design Using H-Spice", International Journal of Recent Technology and Engineering, vol. 8, no. 2 Special issue 5, pp. 22-27.

[5] Jac Fredo, A.R., Abilash, R.S., Femi, R., Mythili, A. \& Kumar, C.S. 2019, "Classification of damages in composite images using Zernike moments and support vector machines", Composites Part B: Engineering, vol. 168, pp. 77-86.

[6] Kathiravan, P. \& Govindaraju, C. 2019, "Design and evaluation of ultra gain isolated DC-DC converter for photovoltaic system", International Journal of Engineering and Advanced Technology, vol. 8, no. 5, pp. 2646-2651.

[7] Kripa, N., Vasuki, R. \& Kishore Kanna, R. 2019, "Realtime neural interface controlled au-pair BIMA bot", International Journal of Recent Technology and Engineering, vol. 8, no. 1, pp. 992-994.

[8] Mohanraj, Meenaa Kumari, M., Philomina, S. \& Jasmin, M. 2019 , "In-situ humidity measurement of hydrogen fuel cell car using MEMS sensor", International Journal of Recent Technology and Engineering, vol. 8, no. 1, pp. 41-43.

[9] Velmurugan, T. \& Prakash, S. 2019, "Artificial intelligent based distribution automation of swift fault detection isolation and power restoration for HT network", International Journal of Innovative Technology and Exploring Engineering, vol. 8, no. 6, pp. 1-6.

[10] Dwarakesh, K. \& Prem Kumar, G. 2019, "Five-level inverter based sequential boost system using fuzzy logic controller", International Journal of Innovative Technology and Exploring Engineering, vol. 8, no. 6, pp. 12-19.

[11] Anne Gifta, A. \& Hemavathi, G. 2019, "Analysis of grid tied solar PV system using ANFIS Algorithm", International Journal of Innovative Technology and Exploring Engineering, vol. 8, no. 6, pp. 312-316.

[12] Jayavel, R., Rangaswamy, T.R. \& Prakash, S. 2019, "Efficient grid management system with renewable and conventional power sources", International Journal of Innovative Technology and Exploring Engineering, vol. 8, no. 6, pp. 287-289.

[13] Hemavathi, G. \& Maheshwaran, S. 2019, "Proportional resonant controlled high gain step-up converter system with improved response", International Journal of Innovative Technology and Exploring Engineering, vol. 8, no. 6, pp. 317-323.

[14] Periyaazhagar, D. \& Irusapparajan, G. 2019, "Design and completion of asymmetric single phase 27 level cascaded mli for various pwm scheme", International Journal of Innovative Technology and Exploring Engineering, vol. 8, no. 6, pp. 792-797.

[15] Mahalakshmi, V. \& Vijayaragavan, S.P. 2019, "PV based power electronic converters for high voltage DC applications", International Journal of Recent Technology and Engineering, vol. 7, no. 6, pp. 670-674.
[16] Irusapparajan, G., Periyaazhagar, D., Prabaharan, N. \& Rini Ann Jerin, A. 2019, "Experimental verification of trinary DC source cascaded h-bridge multilevel inverter using unipolar pulse width modulation", Automatika, vol. 60, no. 1, pp. 19-27.

[17] Sangeetha, G., Sherine, S., Arputharaju, K. \& Prakash, S. 2019, "On Line Monitoring of Higher Rated Alternator using Automated Generator Capability Curve Administer", Proceedings of the IEEE International Conference on \&amp;quot;Recent Trends in Electrical, Control and Communication\&amp;quot;, RTECC 2018, pp. 176.

[18] Bycil, V.J. \& Wiselin, M.C.J. 2019, "Modeling and analysis of vibration energy harvesting system using piezo stack", International Journal of Mechanical and Production Engineering Research and Development, vol. 9, no. Special Issue 1, pp. 523-533.

[19] Sripada, A., Warrier, A., Kapoor, A., Gaur, H. \& Hemalatha, B. 2018, "Dynamic lateral balance of humanoid robots on unstable surfaces", International Conference on Electrical, Electronics, Communication Computer Technologies and Optimization Techniques, ICEECCOT 2017, pp. 539.

20] Srinivasan, S., Thirumalaivasan, K. \& Sivakumaran, T.S. 2018 "Performance evaluation of double-output luo converters", Journal of Advanced Research in Dynamical and Control Systems, vol. 10, no. 10 Special Issue, pp. 870-878.

[21] Karthikayen, A. \& Selvakumar Raja, S. 2018, "A skellam distribution inspired trust factor-based selfish node detection technique in MANETs", Journal of Advanced Research in Dynamical and Control Systems, vol. 10, no. 13, pp. 940-949.

\section{AUTHORS PROFILE}

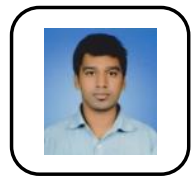

K.Dwarakesh*,Assistant Professor, Department of EEE,Bharath Institute of Higher education and research, Tamilnadu, India.

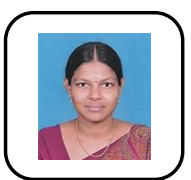

Rathika R,Assistant Professor, Department of EEE,Bharath Institute of Higher education and research, Tamilnadu, India.

Aarthi Suriya S,Assistant Professor, Department of EEE, Bharath Institute of Higher education and Research, Tamilnadu, India. 